\title{
TRADUZIR LÍNGUAS SEM PADRÃO: VARIAÇÃO E NORMA NO CATALÃO DO SÉCULO XIX ${ }^{1}$
}

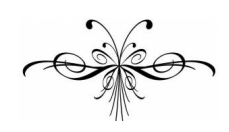

\author{
FRANCISCO JAVIER CALVO DEL OLMO ${ }^{2}$
}

\begin{abstract}
Resumo: Este artigo examina especificidades decorrentes em projetos de tradução que propõem trabalhar com textos escritos em línguas sem padrão ou escassamente padronizadas. Para tanto, problematizamos algumas especificidades relevadas em um corpus de poesia em língua catalã do século XIX. Primeiramente, apresentamos de maneira concisa o contexto histórico, linguístico, literário e cultural dos territórios de línguas catalã durante a segunda metade do século XIX, época em que um grupo de intelectuais e escritores reivindica a língua a partir do uso que eles próprios fazem do idioma. Em seguida, mostramos algumas das dificuldades encontradas por esses autores ao usarem uma língua sem padrão como veiculo de expressão literária e fazemos uma classificação dos dialetalismos, vulgarismos, arcaísmos e estrangeirismos identificados. Por fim, propomos estratégias que considerem o espaço polilinguístico captado pelo texto fonte na língua de chegada.
\end{abstract}

Palavras-chave: línguas não padronizadas; tradução poética; língua catalã.

\begin{abstract}
This paper examines specific issues arising on translation projects that propose to work with texts written in languages no or low standardized. Therefore, we question particular phenomena of a poetry corpus in Catalan language of the nineteenth century. First, we present concisely the historical, literary, linguistic and cultural context of Catalan territories during the second half of the nineteenth century, when a group of intellectuals and writers claim the language from the use they make own language. Right after, we reveal some of the difficulties encountered by these authors to use a nonstandard language as a vehicle of literary expression and make a classification of dialectalisms, vulgarisms, archaisms and loanwords in the texts. Finally, we propose strategies that consider the polilinguistic space captured by the source text in the target language.
\end{abstract}

Keywords: nonstandard language; poetic translation; Catalan language.

\footnotetext{
${ }^{1}$ Este artigo apresenta alguns dos resultados de minha tese de doutorado em Estudos da Tradução (PGET-UFSC) que recebeu o apoio da AECID-MAEC (Agencia Española de Cooperación Internacional y Desarrollo) e da CAPES (Coordenação de Aperfeiçoamento de Pessoal de Nível Superior).

${ }^{2}$ Francisco Calvo del Olmo é formado em Línguas Neolatinas pela Universidade Complutense de Madrid, Espanha (2009), mestre em Pesquisa em Língua Espanhola (2011) pela mesma universidade e doutor em Estudos da Tradução (2014) pela Universidade Federal de Santa Catarina. Atua como Professor Auxiliar de Língua Espanhola na Universidade Federal de Integração Latino-Americana, UNILA, em Foz de Iguaçu; tem publicado artigos em periódicos e capítulos de livros no Brasil, na Argentina, na Espanha e na Colômbia.
} 
A tradução entre línguas modernas permite trabalhar a partir de normas padrão bem consolidadas. Isto se reflete também na existência de imensas fontes de consulta: gramáticas e dicionários monolíngues, bilíngues, de antônimos e sinônimos; assim como é provável que tanto a língua de partida como a língua de chegada possuam produções textuais nos mais diversos gêneros, tradições literárias análogas e mesmo um acervo de obras traduzidas entre elas. O somatório desses elementos auxilia o labor do tradutor que pode consultar todas essas fontes durante o desenvolvimento do seu projeto de tradução.

A situação muda radicalmente para aqueles tradutores ou pesquisadores que se proponham trabalhar com obras compostas em línguas com um escasso grau de padronização que, concomitantemente, costumam ser línguas minoritárias faladas por grupos pouco numerosos e com uma tradição textual fragmentária ou de criação recente.

Este artigo examinará brevemente algumas dificuldades que balizam projetos de tradução inscritos nesse contexto; mais especificamente aquelas derivadas da variação que permeia o texto fonte. Para realizar essa reflexão geral apresentaremos alguns exemplos tomados de um corpus de poetas catalães do século XIX, uma fase identificada na retomada dessa língua como veículo de expressão literária, traduzidos ao português brasileiro ${ }^{3}$. A análise e comentário desses exemplos não só constitui a base empírica de nosso estudo, mas também traz questões válidas para outros projetos de tradução de línguas não padronizadas ou escassamente padronizadas. Desse modo, o nosso trabalho se acrescenta assim àqueles ${ }^{4}$ que, nos últimos anos, tem ampliado o foco dos Estudos da Tradução para além das línguas modernas nacionais ou globais.

\section{O catalão no século XIX: uma língua em estado de emergência}

O Romantismo - como movimento estético, cultural e literário - dominou boa parte do século XIX, adquirindo formas locais segundo os entornos nacionais e linguísticos onde se desenvolveu. No âmbito catalão, a historiografia ${ }^{5}$ adotou, $a$ posteriori, o termo Renaixença para definir o movimento de recuperação da língua e da literatura ligadas ao estabelecimento de uma galeria de mitos nacionais e à progressiva afirmação de uma consciência de comunidade, de povo, que terminou por se organizar no Catalanisme político. Essa palavra foi tomada de um jornal publicado em Barcelona entre 1871 e 1905 cujo título era precisamente La Renaixença (o renascer) e que serviu, junto com outras publicações na difusão da nova literatura e na popularização da leitura em catalão ${ }^{6}$. Este movimento teve características específicas na Catalunha, no País Valenciano e nas Ilhas Baleares; ou seja, embora todos os territórios de fala catalã tenham participado, a Renaixença não teve a mesma intensidade em todas as áreas, pois não era a mesma a situação da língua em cada território. Finalmente, resulta complicado determinar o momento em que a Renaixença, deixou de ter vigência; enquanto alguns a limitam ao século XIX ou-

\footnotetext{
${ }^{3}$ A antologia, editada em língua original e traduzida para o português brasileiro, pode ser consultada pelo leitor em Olmo (2014 p. 209-334).

${ }^{4}$ Vide Cronin (1998) e Branchadell e Lovell (2005).

${ }^{5}$ Ribera Llopis (1982), Rubió i Balaguer (1989), Lleal (1992) e Gabriel (1995).

${ }^{6}$ Além disso, Renaixença se opõe a Decadència (decadência), palavra ambígua e suscetível de inúmeras interpretações, que abrange o longo período de três séculos (XVI, XVII e XVIII).
} 
tros a prolongam até o início de século XX. Em qualquer caso, a chegada do novo século e o Simbolismo deslocou o centro da criação artística para outros movimentos como o Noucentisme ${ }^{7}$.

Assim, os poetas que começam a escrever em catalão nesse período se engajam na reivindicação da língua a partir da própria língua; ou seja, o catalão é meio e fim. Os intelectuais discutem o papel da língua na identidade da comunidade, a necessidade da criação de uma norma, a importância do letramento em língua materna, a origem e história do idioma entre as línguas neolatinas além de outros assuntos; e é o mesmo catalão o veículo dessa produção artística e intelectual. A construção identitária e a criação de uma norma linguística trilham, de mãos dadas, um percurso não isento de conflitos e de exaltadas disputas literárias, culturais e políticas.

Assim, os poetas escrevem uma língua sem padrão no sentido da não existência de uma norma bem definida ou uma autoridade que a imponha, portanto, cada um se sente livre para introduzir no seu texto toda uma série de possibilidades e variações, às vezes, com fins estéticos e literários. Tal estado de emergência - entendida como urgência e surgimento - deixa uma série de marcas no corpus; uma tradução desses textos na variedade padrão da língua de chegada incorreria no apagamento tais marcas. Por esse motivo, faz-se necessária uma análise minuciosa dos diferentes níveis desse espaço polilinguístico a fim de adotar estratégias que situem tais especificidades no centro do da atividade e da reflexão tradutória.

\section{As línguas históricas: entre a variação e a norma}

De acordo com Berman (2007), as produções literárias se caracterizam, pelo fato de captar, condensar e mesclar todo o espaço polilinguístico de uma comunidade; por mobilizar e ativar "a totalidade das 'línguas' coexistindo numa língua" (p. 46). Nesse mesmo sentido, a língua pode ser entendida como um continuum de dialetos, registros, estilos e discursos:

There can be no question of choosing between adhering to the constants that linguistics extracts from language or placing them in continuous variation because language is a continuum of dialects, registers, styles, and discourses positioned in a hierarchical arrangement and developing at different speeds and in different ways. (VENUTI, 1998, p.29-30)

Assim a variação aparecerá em cada nível, em cada língua, constitutiva de uma língua histórica. Sobre essa variação instável, a padronização busca firmar uma forma estável: "a padronização consiste na imposição de uniformidade a uma classe de objetos” (MILROY, 2011, p. 51). Portanto, é possível recortar um estado anterior à padronização considerado pelas culturas de língua padrão como um estado natural:

Partindo de certo paternalismo etnocêntrico, o falante minoritário é visto como uma espécie de bom selvagem linguístico, um falante felizmente desregrado, não submetido às imposições normativas das sociedades modernas. As tentativas de construção e elaboração de uma língua nesse contexto são percebidas como uma

\footnotetext{
${ }^{7}$ Não tentamos aqui fazer uma síntese da história da literatura catalã, empresa excessiva para os nossos objetivos atuais, mas apenas apresentar, de maneira concisa, alguns fatos necessários para contextualizar nosso estudo.
} 
aberração que viria tirar o falante minoritário do seu “estado natural” prénormativo. (LAGARES, 2011, p. 172)

Cabe dizer que a padronização não é um fato universal para as línguas e, no processo de padronização, as variações costumam responder à vontade de certos autores ou grupos que não aceitam se submeter à uniformização. Uma língua padronizada assume a preeminência da variedade padrão por sobre todas as outras, delimitando assim uma dicotomia entre padrão e não padrão. Por conseguinte, os falantes passam a considerar que "quando houver duas ou mais variantes de alguma palavra ou construção, somente uma delas pode estar certa” (MILROY, 2011, p. 58); aquela que corresponda à forma canônica do idioma. O mesmo autor ainda acrescenta que "as autoridades (geralmente não nomeadas) das quais dependem os falantes (e seus professores) têm acesso privilegiado aos mistérios da língua e têm algo do status de sumo sacerdotes” (ibid., p. 60). Porém, a padronização da língua, “em todos os níveis e em ambos os canais da transmissão, nunca está plenamente acabada, e o padrão está sempre num processo de manutenção” (ibid., p. 68).

No contexto linguístico, cultural e literário aqui recortado, os escritores da Renaixença cumprem essa função de autoridades linguísticas autoproclamadas com a missão de determinar quais formas devem ser valorizadas (consideradas legítimas) e quais devem ser evitadas. Consequentemente é plausível considerar que a escolha de uma ou outra forma por um autor responda a uma decisão consciente, acorde com seu projeto glotopolítico, estético e literário. Como qualquer outra língua histórica, o catalão apresentava na época de seu ressurgir literário variações no domínio geográfico e no âmbito social; e, no mencionado processo de padronização, alguns dos traços avaliados como marcantes ou característicos dessa salientaram-se a fim de melhor defini-la, "balizando as fronteiras entre tal língua e outras com as quais ela está geneticamente aparentada ou se acha em contato" (MONTEAGUDO, 2011, p. 27). O eminente gramático catalão Pompeu Fabra assume a função de auxiliar os escritores procurando um modelo literário entre as diferentes camadas (diatópicas, diastráticas, diacrônicas, diafásicas) e expõe os desafios enfrentados pelos poetas do século XIX:

Els nostres escriptors es trobaren, en iniciar-se la Renaixença, amb una llengua empobrida, deformada, malmesa per innombrables castellanismes, la qual no podien pas adoptar com a llengua literària sense tractar de depurar-la, d'enriquirla, de realçar-la. I això no es podia realitzar sense una coneixença perfecta de la llengua antiga i dels dialectes actuals, que ens guiés en la tasca dificilíssima de descobrir i remeiar les desviacions sofertes per la llengua; no es podia realitzar sense una coneixença exacta de les lleis de l'evolució del llenguatge i de la història de les altres llengües literàries. Els nostres escriptors, doncs, havien de desitjar ardentment l'aparició del filòleg i gramàtic, que vingués a ajudar-los en l'obra patriòtica de refer la llengua, la qual, a través de tants segles de decaïment literari i de subjugació al castellà, ens havia arribat tota malaltissa i empobrida, i la qual tots ambicionàvem de veure altra vegada ocupant el rang que li pertoca dins la família de les llengües neollatines. (FABRA, 1980, p. 135-136)

Em seguida, aprofundaremos a exposição da variação enunciada por Fabra a partir de exemplos extraídos do corpus, mas antes devemos problematizar como essa variação influi na tarefa do tradutor. 


\section{Escrever e traduzir uma língua sem padrão}

Dialogando com argumentos já apresentados neste artigo, Levý (2011, p. 97) chama a atenção a respeito do empobrecimento do texto na língua de chegada se a norma padrão substitui a polifonia linguística do original: "If the foreign language is simply substituted by the target language in its standard form, its characterizing value is lost”. Além disso, enumera algumas tendências lexicais que o tradutor adota; a saber: a generalização (generalisation), o nivelamento (nivelisation) e a variação lexical limitada (limited lexical variation).

A primeira, generalização, é definida como a designação geral dentre um conjunto de sinônimos ou quase sinônimos: "In translation it is the general designation, the least vivid amongst the set of near-synonyms, that comes to mind most readily" (ibid., p. 108). A generalização faz-se inevitável no caso de expressões regionais que costumam ser traduzidas por expressões próprias da língua padrão (ibid., p. 110). A segunda tendência provoca o nivelamento, uma neutralização dos traços mais marcados do original que assim perdem, por vezes, o seu valor expressivo: "Emotionally coloured expressive means sometimes lose their stylistic value in translation if rendered by a neutral, colourless expression” (ibid., p. 111). E, finalmente, a variação lexical limitada se apresenta como tendente a não explorar todos os recursos que a variação entre sinônimos e nuances de significado disponibiliza o léxico da língua de chegada: "In translation, the resources of a language in terms of synonyms for subtle differentiations of meaning are generally under-exploited" (ibid., p. 113).

Assim sendo, é necessário classificar as marcas que a falta de um padrão deixa nos textos fonte a fim de poder definir uma estratégia tradutória que dê conta delas.

\subsection{Dialetalismos}

Começaremos examinando a variação representada pela convivência de palavras que mudam de um território para outro; ou seja, os dialetalismos ou traços linguísticos próprios de um dialeto. Resulta fundamental a imbricação geográfica na produção artística do grupo de poetas aqui estudado que se nutre de todo um acervo de falares. A variação lexical ligada à geografia é entendida pelo grupo como um verdadeiro tesouro; desse modo, o intuito desses intelectuais corresponde com o trabalho de outros escritores românticos. Nesse sentido, Berman (2002, p. 286) fala da procura do "Sprachlichkeit, a força falante da língua comum, força falante que vem de seu enraizamento pluri-dialetal”. O processo de escolher uma variedade por sobre as outras cria uma dicotomia, uma tensão entre padrão e dialeto:

As variedades padrão, na medida em que podem ser claramente caracterizadas, têm propriedades a mais que os assim chamados dialetos não padrão (na medida em que estes podem ser claramente caracterizados), e nossa discussão sugeriu fortemente que as línguas que têm variedades padronizadas são, em alguns aspectos, entes diferentes das que não as têm. (MILROY, 2011, p. 70)

No âmbito catalão, Barcelona, como grande urbe industrial, teve um peso considerável durante o processo de codificação servindo, em boa medida, de base para a língua padrão, o catalão central. 


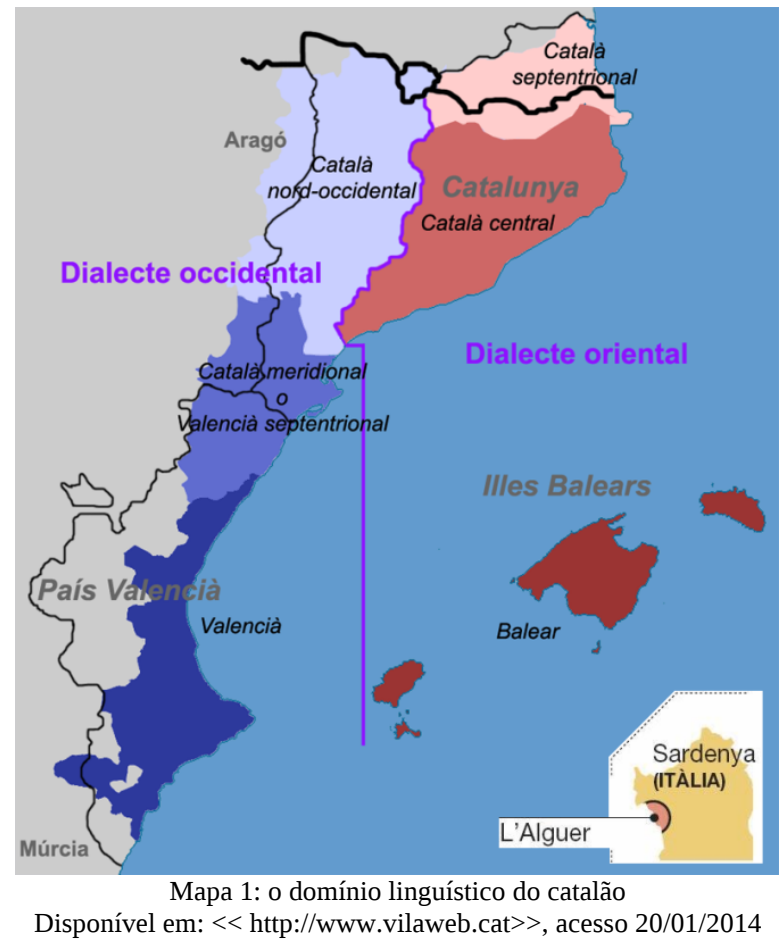

O Mapa 1 permite visualizar os territórios de fala catalã onde se distribuem os mais de onze milhões de locutores com os que essa língua conta na atualidade. Nele, a linha roxa divide verticalmente o domínio em dois dialetos: catalão ocidental e catalão oriental. Cada um deles, por sua vez, é dividido em vários falares, marcados em tons de vermelho e rosa para o dialeto ocidental e em tons de violeta e lilás, para o dialeto oriental. O Alguer, cidade da costa ocidental da ilha de Sardenha, foi anexado ao mapa para completá-lo.

A fim de ilustrar como os dialetalismos representam uma especificidade do processo tradutório, analisaremos alguns exemplos. Para tanto, consultamos dois dicionários disponíveis em sítios eletrônicos: o diccionari.cat ${ }^{8}$, obra monolíngue descritiva do catalão contemporâneo, e o Diccionari català-valencià-balear (DCVB) de Alcover e Moll, editado pelo Institut d'Estudis Catalans ${ }^{9}$. Vale dizer que aquelas palavras que os dicionários descrevem como vozes dialetais podiam ser percebidas de forma diferente na época dos autores do corpus.

Nos versos 153 e 154 de A la llengua catalana de Bonaventura Pons i Fuster (apud. OLMO, 2014, p. 276), encontramos um adjetivo pouco usual no padrão contemporâneo: girbada.

Per ella molts m'han deixat com a tonta i mal girbada ${ }^{10}$

\footnotetext{
8 Esta obra, publicada pelo grupo editorial Enciclopèdia Catalana, está disponível em $<<$ http://www.diccionari.cat/ >>.

${ }^{9}$ Esse dicionário é um inventário lexical da língua catalã, publicado entre 1943 e 1959 em dez volumes; desenvolvido por Antoni Maria Alcover i Sureda e Francesc de Borja Moll i Casasnovas com a colaboração de Manuel Sanchis i Guarner e de Aina Moll i Marquès. Como o título sugere, essa obra se propõe abranger as principais variedades do idioma. Disponível em $<<$ http://dcvb.iecat.net. $>>$

10 Tradução para o português brasileiro do trecho citado: Por ela muitos me deixam/ como tola e desleixada.
} 
A busca do adjetivo girbada nos dois dicionários mencionados forneceu as seguintes informações:

Girbat, -ada [variant del rossellonès gerbit, girbit 'arreglat, engiponat', der. de l'ant. gerd 'herba, gleva' (v. gerber)] adj Forjat. Com va girbada, aquella dona. (disponível em $<<$ diccionari.cat $>>$ )

GIRBAT, -ADA adj. que s'usa sempre precedit d'un dels adverbis ben o mal (ben girbat, mal girbat): ben arreglat, mal arreglat. Era una dona alta i mal girbada, Ruyra Parada 76. (disponível em <<dcvb.iecat.net $>>$ )

A primeira fonte informa a variante à qual pertence essa voz: o rosselhonês, dialeto mais setentrional do catalão oriental; ao mesmo tempo, recolhe outras variantes e a origem da palavra. A segunda fonte, por sua vez, não explica nem a localização geográfica da palavra nem a origem se limitando a descrever os usos que essa possui: sempre precedida dos advérbios mal ou ben; acrescentando ainda um exemplo literário. Em síntese, girbat, -ada é uma palavra rosselhonesa equivalente ao mais geral plantat,-ada, arreglat,-ada.

Uma vez delimitada a especificidade da palavra, podemos procurar estratégias tradutórias para o português brasileiro. No presente caso, escolhemos o adjetivo desleixada que contém a carga semântica de mal girbada e ademais possui o mesmo número de sílabas e mantém a assonância (aCa) do verso original. Porém, o valor localizado geograficamente do original fica diluído na tradução.

Os poemas de Marià Aguiló i Fuster - La llengua materna XVII (apud. OLMO, 2014, p.312-319) e L'arbre de la pàtria (apud. OLMO, 2014, p. 320-325) merecem especial interesse já que o autor era de Maiorca; isto é, usuário de uma variante fortemente caraterizada dentro do continuum catalão. Os dois poemas estão permeados de formas próprias do catalão baleárico. Marià Aguiló usa formas de segunda pessoa do plural com a desinência pessoal - $a u$, onde o catalão padrão atual apresenta - eu; assim, em La llengua materna, temos escoltau. Também usa sistematicamente formas de primeira pessoa sem desinência pessoal, como ompl, aim (no padrão omplo, amo), que nesses poemas assumem uma função métrica já que a desinência pessoal acrescentaria uma sílaba alterando o cômputo silábico. Além de formas morfológicas baleáricas, merecem nossa análise alguns exemplos léxicos extraídos de L'arbre de la pàtria. Nos versos 19 e 20 aparece o substantivo esponera: "de l'esponera que feia/ no ens en resta una meitat” (“do viço que outrora tinha/ resta-nos metade só”, em nossa tradução). O diccionari.cat indica que esponera é "mot propi del mallorquí”; isto é, palavra própria maiorquina. E fornece como sinônimo da língua padrão ufana. O DCVB por sua vez traz a seguinte definição como terceira acepção da palavra:

ESPONERA f. 3. Ufania, exuberància; eixamplament abundós d'una cosa cap a l'exterior; especialment, abundància de fullatge, de brancam, i per ext., d'ornaments i adherències del vestit (Mall.); cast. ufanía, lozanía. «Madò Bet, s'aufabeguera | que teniu en es portal | haureu mester sa destral | per tallar-li sa ramera; | ella duu més esponera | que qualsevol olivera | de dins s'hort de La Real» (cançó pop. Mall.). Ningú sap com era | que dins l'esponera | de l'hort senyorívol, | fent-lo més ombrívol, | creixia la rama d'antiga olivera, Alcover Cap al tard 56. Damunt la ribera | hi ha tombs de bambú cabanyes fenyent; | els arbres ho ensostren amb verda esponera,Carner Lluna 178. Posar-ho tot en esponera: treure massa fullatge i fer poc fruit. «Aquest blat duu molta d'esponera»: es 
diu d'un blat ufanós, que creix amb molta força. 4. fig. Cosa abundant i inútil o de poca substància; cast. hojarasca. La noblesa de nom no és més que esponera, Penya Mos. III, 32. Avuy s'usa una altra gent $\mid$ que du molta d'esponera, Ignor. 35. (disponível em <<dcvb.iecat.net, 2014>> grifos meus)

De acordo com o segundo dicionário, esponera pode ser traduzido por viço como aparência exuberante de uma planta, vigor e florescência dos vegetais.

Não foi objetivo da presente seção apurar todas as vozes de origem dialetal que concorrem no corpus, mas apenas sublinhar tal especificidade a partir de alguns exemplos e evidenciar a dificuldade da tradução para o português brasileiro, língua que conta com uma sólida tradição normativa, do espaço pluridialetal do catalão da época. E, se, por um lado, entendemos de acordo com Levý (2011, p. 98) que um dialeto em particular ou uma língua estrangeira está suficientemente próxima ou unida a uma particular região para ser um substituto desejável; por outro, concordamos com a asserção de Berman (2002) segundo a qual "a relação da língua com seus dialetos é uma relação mútua e diferenciada; os dialetos são dialetos dessa língua, só têm sentido de serem dialetos no espaço desta última” (p. 297). A justaposição das duas afirmações conduz a certa contradição demostrando assim que não existe um posicionamento único para compreender o papel da pluralidade dialetal no ato tradutório.

\subsection{Vulgarismos}

A presença de marcas dialetais não apura as especificidades linguísticas já que também há palavras que, se as buscássemos em um dicionário moderno de catalão, não as encontraríamos. Trata-se de vulgarismos; usos populares que diferem das formas padronizadas, emanadas da academia, e consequentemente carecentes de prestígio. Os vulgarismos são fenômenos internos, endógenos, de variação e mudança linguística nos quais a analogia das formas mais comuns exerce sua influência sobre formas irregulares de acordo com as tendências inerentes às estruturas morfossintáticas, léxico-semânticas e fonético-fonológicas do idioma. O diccionari.cat define vulgarismo da seguinte forma, colocando alguns dos vulgarismos socialmente mais difundidos ou marcados do catalão: "Expressió o fenomen lingüístic de caràcter vulgar, no admès en la llengua normativa. Ex.: sapigut per sabut, crusos per crus, havés per hagués”. Neste ponto, é importante salientar que o Diccionari Català-Valencià-Balear fornece uma listagem de formas para a mesma palavra habitualmente com comentários que adscrevem cada uma delas a determinada variante geográfica ou social, trazendo também a origem do étimo. A apresentação de cada entrada nessa obra é diferente dos dicionários atuais que, se monolíngues, fazem corresponder uma palavra e uma definição ou, se bilíngues, fazem corresponder o termo nas duas línguas, mas raramente apresentam uma abundância de formas para uma entrada só. Entretanto, parece que aquele dicionário não entende a variação como secundária, estigmatizada e carente de relevância, mas como uma parte central na definição e caracterização de cada voz, um recurso à disposição do escritor e do falante.

A seguir examinemos alguns exemplos; no poema Oda a la Pàtria (apud. OLMO, 2014, p. 252-255) de Carles Aribau, encontramos várias palavras que a atual norma linguística não reconhece. Assim superbe por soberg (soberbo) ou innocenta forma hipercaraterizada do adjetivo innocent, que apresenta uma desinência feminina por analogia como outros adjetivos que, na língua padrão, têm uma 
forma masculina e feminina como fort/forta, comú/comuna ou verd/verda. O título do poema de Rubió i Ors Mos Cantars (apud. OLMO, 2014, p. 256-261) apresenta o substantivo cantars, considerado vulgarismo onde a língua padrão prefere cant ou càntic. Igualmente o título de Los Cants del Laletà (apud. OLMO, 2014, p.262-267) de Blanch Cortada contém uma palavra que requisita uma análise detalhada: o adjetivo laletà. Essa forma só aparece no Diccionari Català Valencià i Balear (DCVB) como variante vulgar de laietà, forma que também possui uma entrada na mesma obra:

LALETÀ, -ANA $m$. i f . Nadiu o propi de les tribus ibèriques que en temps de la invasió romana ocupaven la costa oriental de la Península Ibèrica des d'Empúries fins al Llobregat; cast. laletano.Aydats dels laletans los feyen cruel guerra, Boades Feyts 12.

ETIM.: pres de Laletani, nom que els historiadors romans donen a les dites tribus. (disponível em $<<$ dcvb.iecat.net $>>$ )

LAIETÀ,-ANA $m$. i f . Nadiu o propi d'una tribu ibèrica que en temps de la dominació romana ocupava la Regió on actualment està situada Barcelona; cast. layetano.LAIETÀ,-ANA m. i f. (disponível em <<dcvb.iecat.net $>>$ )

Assim, Laletà, -ana é um adjetivo pátrio referido às tribos que ocuparam uma parte da atual Catalunha antes da invasão romana que veio unificar todos esses territórios na província da Hispania Citerior Tarraconensis. Os poetas românticos recuperam esse nome vinculado à essência do patriota catalão em um exercício análogo ao que une o adjetivo luso, lusitano a Portugal ou íbero a Espanha (ou até ao conjunto da Península Ibérica). Todavia Laletà, -ana não aparece no diccionari.cat onde só se registra a forma laietà, -ana com igual valor:

Laietà,-ana: 1 adj Relatiu o pertanyent als laietans. 2 m i f HIST Individu d'un poble preromà, ibèric, establert a les comarques del Maresme, el Barcelonès, el Baix Llobregat i el Vallès. (disponível em $<<$ diccionari.cat $>>$ )

Ao fazer a tradução para o português, escolhemos a forma laietano. Igualmente passamos para o plural o título do poema Los Cants del Laletà com o intuito de reforçar no leitor a ideia de que se trata de uma comunidade - os laietanos pois, de outro modo, poderia ficar velada pela opacidade do adjetivo pátrio. Colocamos cantos em singular com o sentido do canto, sinônimo da voz, a canção, a epopeia desse povo expressada pelos versos do trovador. Como resultado, obtivemos $O$ canto dos laietanos.

Avançando na apresentação dos vulgarismos levantados no corpus, devemos examinar a composição de Víctor Balaguer, destacado defensor da padronização da língua, que, no entanto, usa formas hoje consideradas vulgares em poemas como Ausias March (apud. OLMO, 2014, p. 296-311) onde aparece, por exemplo, pretenguda (forma vulgar do particípio passado feminino pretesa do verbo pretendre; tencionar, pretender). A forma aixís do adverbio de modo així (assim), presente no verso 100 do mesmo poema: aixis a mos oïdos ressonà; aparece também em outros textos do corpus. Este advérbio apresenta grande variação no domínio da língua catalã segundo o DCVB: 


\begin{abstract}
Var . form. -1 . Aixic ( Ciutadella ) . -2 . Aixiques, forma usada sevamajoria dels al · lots ( ibid. ) . -3 . Aixin ( Perpinyà , Canet de Ross . ) . -4 . Aixina ( Recollida al Lluçanès, Ponts , Massalcoreig , Reus , Peníscola , Morella , Benassal , Forcall , Plana de Castelló , Onda , Val ., Gandia , St Lluís de Men . , EIV . , Formentera ) . I a sos peus agenollant - me, | aixina li vaig pregar, Llorente Versos , ii , 126 . « Més m'estim veure'm aixina , | no desconfiant de Déu , | que no posseir riqueses | si han d' esser contra gust meu » ( cançó pop ., EIV . ) . -5 . Aixines , forma intensiva ( Lluçanès, Penedès , Solsona , Tremp , Massalcoreig , Manacor , Artà , Men . ) . " És aixi que ho tenc de fermentació ? - Aixines » (Ciutadella ). -6 . Aixinos, forma intensiva que altres sols s'empra absolutament, sense lligar - se AMB Altra partícula ( Mall ) . -7 . Aixinetes, forma intensiva que altres sols s'usa de manera absoluta ( Mall ) . 8 . Aixins ( Ross., Barc ., Penedès, Isavarri , Pla d'Urgell, Men . ) . Ei , axins al Menys ho Diuen, Oller Rur . urb . , 47. -9 . Aixinses ( Cardona ) . Axínses ray ! sospirà la Quíusa , Girbal Oratjol 88. -10 . Aixintes ( Tortosa ) . -11 . Aixit ( Vilaller, Pont de S. , Bonansa ) . -12 . Aixuixí , forma intensiva ( Mall , Men . ) . Te usos especials, que explicam al lloc alfabètic DE PAGAMENT ( V. aixuixí ) . -13 . Aixuixic, forma intensiva con los mateixos usos d' aixuixí ( Men. ) . -14 . Aixuixiques , forma usada sevamajoria entre a els al · lots (Ciutadella ) . -15 . Aixuixines, forma intensiva ( Mall , Men . ) . -16 Aixuixinos, forma intensiva con los mateixos usos d' aixuixí ( Mall ) . -17 . Aixuixinetes, forma diminutiva que s'empra per expressar les conformitat i Satisfacció per la manera de fermentació una cosa ( Mall ) . -18. Aixuatxí , forma intensiva usada a Menorca Amb la mateixa aplicaci que feme assignada a aixuixinetes . "És aixi que ho vols ? - Aixuatxí » (Ciutadella ) . -19 . Assetsuaixí o assetssuaixí ( Mall ), con els mateixes aplicacions de aixuixí ; però Més intensiva ( V. Assus - suaixí ) . -20 . Jutxuixí : forma molt expressiva , deformació per just suaixí ( Mall ). (disponível em $<<$ dcvb.iecat.net $>>$ )
\end{abstract}

Várias dessas formas consideram-se vulgares (como aixís ou aixina) enquanto outras são expressivas (aixuatxí ou jutxuixí) mostrando como variação diatópica, diastrática e diafásica conflui, às vezes, numa mesma voz. Em síntese, ao carecer ainda da forte consciência normativa do escritor de uma língua padronizada, a diferenciação entre norma padrão e língua popular parece não estar nitidamente definida.

\title{
3.3. Arcaísmos
}

Em terceiro lugar, observamos no corpus uma dinâmica que contrasta com a língua poética baseada na língua falada; isto é, o recurso a vozes e construções morfossintáticas que não correspondem a variedades geográficas nem sociais, mas a estágios mais antigos da língua. Estes são os arcaísmos, definidos no diccionari.cat como "1. Mot, forma o construcció antiquats, caiguts en desuetud 2. Ús de mots, de formes o de construccions antiquats". O arcaísmo não abrange apenas palavras caídas em desuso ou consideradas antiquadas, mas também expressões ou construções sintáticas que se afastam do uso comum. Cabe dizer que os estudos filológicos e a recuperação das fontes medievais, fatos coetâneos aos poetas da Renaixença, possibilitaram um conhecimento aprofundado do estado da língua durante o período medieval. Intelectuais como Bofarull tiveram acesso ao Arquivo da Coroa de Aragão que guardava documentos pertencentes aos séculos medievais e também às centúrias da nomeada Decadència.

De acordo com King (2005), essa memória dos autores clássicos é retomada pelos poetas da Renaixença que, além de admirar a obra dos trovadores occitanos antigos, se declaram discípulos de Ausiàs March e reivindicam o desenvolvimento cultural da língua catalã durante o Medievo. Este escritor valenciano do século XV, Ausiàs March, introdutor no âmbito peninsular de formas poéticas proce- 
dentes da Itália como o soneto, recebe nos versos que Balaguer lhe dedica os títulos de "Petrarca llemosí" e "rossinyol dels trobadors". Nesse poema, os versos de Balaguer se misturam com fragmentos tomados do próprio March.

Dessa forma, a rica tradição literária fornecia modelos e conformava um marco para o cultivo da poesia. Isto levou alguns intelectuais a considerarem tudo aquilo que se afastava desses como produto da corrupção ou da degradação do idioma, resultado, em última instância, da dominação estrangeira; ao mesmo tempo, todas aquelas formas que se correspondiam com as presentes em textos antigos recebiam preferência a pesar de poderem soar afetadas ou ser simplesmente desconhecidas. De acordo com Milroy (2011, p. 77), "a historicização é um fator-chave na legitimidade”; assim “dar uma história a uma forma era, no mesmo gesto, legitimar essa forma” (ibid., p. 81).

Neste ponto, vale salientar a onipresença do artigo definido masculino lo/s considerado hoje "Forma arcaica, dialectal i ocasional de l'article definit o determinat masculí” (disponível em $<<$ diccionari.cat $>>$ ); sendo a forma padrão desse el/s. Vemos no presente caso que forma dialetal e forma arcaica aparecem associadas. A alternância de lo e el no corpus está motivada às vezes pelas necessidades do computo silábico. De novo aqui, o arcaísmo é um recurso a serviço da métrica do poema. Algo similar acontece na Oda a la Pàtria de Carles Aribau com algumas primeiras pessoas de verbos (transport, parl) que em catalão medieval haviam perdido a desinência pessoal $(-o)$, mas que em catalão central padrão foi recuperada. Essas formas apocopadas contêm uma sílaba a menos e assim podem se ajustar às necessidades métricas. No caso de Oda a la Pàtria, consideramos as formas verbais sem desinência de primeira pessoa como arcaísmos e não como dialetalismos -diferente ao explicado sobre a ocorrência de tais formas nos poemas de Aguiló i Fuster - pois o autor, Carles Aribau, se adscreve à Catalunha onde a desinência de primeira pessoa majoritária nos verbos da primeira conjugação é $-O$.

No mesmo poema, a terceira oitava de Oda a la Pàtria começa com o verso "Què val que m'haja atret una enganyosa sort" ("Que vale se me trouxe enganadora sorte”, na tradução), usando a forma arcaica haja do verbo auxiliar haver (cat. central. hagi). De forma análoga ao caso da desinência de primeira pessoa, haja é usada em outros dialetos (valenciano) e se assemelha ao castelhano haya e é igual ao português atual: haja. Evidencia-se de novo que na escolha de determinada forma confluem várias possibilidades e só optamos por qualificá-la, nesse caso, como arcaica por causa da origem do autor (não era valenciano) e do seu estrato (era um escritor culto que deveria reconhecer e rejeitar formas estrangeiras). Ainda no mesmo poema, achamos a forma $I x$, imperativo do verbo eixir (sair) substituído pelo verbo sortir (originalmente surgir que assumiu o sentido de sair). Todavia o verbo eixir se mantém vigente em algumas áreas do domínio linguístico, principalmente em Valência; mostrando mais uma vez quão complicado resulta deslindar dialetalismo e arcaísmo dentro do contexto linguístico e cultural recortado.

A partir dos exemplos extraídos do corpus, podemos inferir que o arcaísmo é um recurso estético e literário a serviço do escritor, permitindo-lhe ainda articular um diálogo com a tradição. Assim, a tradução deverá considerar tais especificidades a fim de manter essas características sem cair em soluções artificiais de acordo com a asserção de Berman (1995, p. 186): "L'archaïsme ponctuel ne se soutient pas et est toujours conduit à devenir archaïsme systématique : seule façon d'éviter le disparate et l'artificiel”. 


\subsection{Estrangeirismos}

Finalmente, nos textos do corpus aparecem elementos lexicais e construções morfossintáticas procedentes do espanhol, língua oficial do Estado centralista onde viviam esses autores. Certamente a proximidade linguística - por serem todas as duas línguas românicas - e a convivência secular - que se manifesta em empréstimos de longa data e influências recíprocas - faz com que os escritores empreguem algumas vozes estrangeiras para cantar as essências da nação própria, fato que pode ser entendido como uma forma de hibridação linguística e cultural. Tais estrangeirismos recebem o nome de barbarismes (barbarismos) que não são necessariamente palavras ou expressões em desacordo com as normas gramaticais ou erros de grafia, significado ou pronuncia, mas segundo o diccionari.cat "Forma lingüística, particularment lèxica, dins una llengua determinada, d'origen estranger, i normativament rebutjada”. Palavras cuja fonética revela que não fazem parte do fundo léxico catalão. A diferença desses empréstimos antigos, para os que a língua vernácula não dispõe de um correspondente, os barbarismos são rejeitados pela norma culta que advoga por recorrer ao acervo léxico e morfossintático vernáculo. Nesse sentido, o linguista francês Hagège (2000) faz uma diferenciação entre o empréstimo léxico (l'emprunt lexical), entendido como "une condition de la vie des langues" e o empréstimo massivo que acontece em situações de diglossia e pode ameaçar a continuidade da língua minoritária: “l'emprunt n'est pas en soi une cause de l'extinction des langues. Il en est une signe inquétant lorsqu'il est envahissant et ne laisse intact aucun domaine” (íbid., p. 97).

Caberia também se questionar a respeito da consciência que os autores do corpus tinham na hora de usar uma palavra ou construção suspeita de ser estrangeira, já que a repetição de certos empréstimos e certos decalques é recorrente. Esse é o caso do adjetivo hermós,-a, muito usado, de acordo com o gosto dos românticos, em poemas como Oda a la Pàtria, Los Cants del Laletà, A la llengua catalana entre outros. Esses autores parecem ignorar a sua procedência estrangeira já que adaptam a palavra aos padrões de flexão do catalão (hermós,-a,os,-es) e não do espanhol (hermoso,-a,-s,-as). Além disso, em Oda a la Pàtria, aparecem outras palavras procedentes do espanhol como agravis $^{11}$ alocada na quarta estrofe:

\footnotetext{
Plau-me encara parlar la llengua d'aquells savis que ompliren l'univers de llurs costums i lleis, la llengua d'aquells forts que acataren los reis, defengueren llurs drets, venjaren llurs agravis. Muira, muira l'ingrat que al sonar en sos llavis per estranya regió l'accent natiu, no plora, que, al pensar en sos llars, no es consum ni s'enyora, ni cull del mur sagrat las lires dels seus avis! ${ }^{12}$
}

\footnotetext{
${ }^{11}$ Em espanhol agravios, catalão padrão greuges e português afronta ou agravo.

${ }^{12}$ Em nossa tradução para o português brasileiro: Gosto ainda de falar a língua desses sábios/que encheram o universo com seu costume e leis,/a língua desses fortes que acataram os reis,/ defenderam seus diretos, vingaram as afrontas./ Morra, morra o ingrato se ao soar em seus lábios/ numa estranha região o acento natal, não chora,/se, ao pensar em seu lar, as saudades ignora,/ nem toma do muro santo as liras dos avós.
} 
O substantivo agravis rima com savis, llavis e avis e responde a certa analogia: onde o castelhano tem - io, o catalão apresenta - i (diccionario diccionari). Consequentemente o autor pode ter dado preferência ao barbarismo por sobre a palavra vernácula (e hoje majoritária) greuges para satisfazer necessidades métricas e rítmicas. A influência da língua espanhola se demonstra igualmente em alguns decalques de estruturas forâneas; por exemplo, no verso 97 de A la llengua catalana lemos: "i allí li doní petons"; em português dar beijos e em espanhol dar besos significa beijar/besar enquanto o catalão prefere fer petons (literalmente fazer beijos).

É interessante acrescentar um barbarismo localizado no verso 24, terceira estrofe de Epigrames (apud. OLMO, 2014, p. 286-289) de Vinader i Nubau:

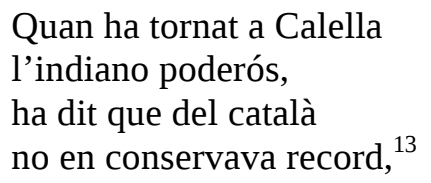

Aqui o autor satiriza a figura dos jovens pobres que partem para fazer fortuna na América e voltam, ao cabo dos anos, ricos como estrangeiros na própria terra. Nas culturas da Península Ibérica essas pessoas eram chamadas de indianos como o Diccionario de la Real Academia de la Lengua Española define: “adj. Dicho de una persona que vuelve rica de América” (disponível em $<<$ rae.es $>>$ ). Neste caso resultaria difícil encontrar uma palavra vernácula tanto em catalão como em português brasileiro. Em síntese, a presença de estrangeirismos é recorrente nos poemas catalães do século XIX seja por necessidades de métrica ou de rima, por uso inconsciente de uma palavra não vernácula ou por ação deliberada.

Os dois poemas de Joan Maragall recolhidos no corpus, Oda a Espanya (apud. OLMO, 2014, p. 326-329) e Els focs d'aquest Sant Joan (apud. OLMO, 2014, p. 330-333), também contêm estrangeirismos mesmo tendo sido compostos na passagem ao século XX, quando o processo de padronização já tinha avançado bastante e os gostos estéticos se aproximavam ao Modernismo. Tal é o caso do barbarismo pervindre pelo padrão esdevenidor (castelhano porvenir, português porvir ou futuro), oïdo por oïda (ouvido), desgarrar por esqueixar (rasgar, esmagar), mariposa por papallona (borboleta), assombrar por espantar, esglaiar (espantar).

Por fim, referente aos barbarismos, cabe mencionar que em Oda a la Pàtria encontramos um galicismo (gal·licisme na tradição lexicográfica catalã) $p a-$ rents por pares: os pais ${ }^{14}$, no verso 10: “com conèixer pogués lo front de mos parents” (“como conhecer posso a testa de meus pais;”, em nossa tradução). Evidenciando assim a influencia de outras línguas de cultura próximas para além do idioma oficial do Estado centralista.

\footnotetext{
${ }^{13}$ Em nossa tradução para o português brasileiro: fez fortuna nas Américas/ e vestiu-se de senhor./ Quando voltou a sua aldeia/ o colono poderoso,/ disse que do catalão/ não conservava lembrança.

${ }^{14}$ Note-se que nas línguas ibero românicas o casal formado por pai e mãe recebe o nome de pais (es. padres, cat. pares) enquanto em francês e em italiano não é assim (fr. père + mère= parents; it. padre + madre $=$ genitori $)$.
} 


\section{Considerações finais}

Em síntese, todas as categorias que foram balizadas no presente artigo permeiam um projeto de tradução que se proponha trabalhar com poesia escrita em catalão no século XIX. Devemos acrescentar que a existência de um padrão aproxima as produções dos falantes em determinados registros, principalmente naqueles que fazem uso culto da língua; entretanto, a falta desse, ou o fato de encontrar-se em processo de construção do padrão, faz com que os textos sejam muito mais sensíveis à variação. Segundo Monteagudo (2011, p. 18), em uma situação de diglossia e conflito linguístico, variação intersistêmica e variação intrassistêmica aparecem "estreitamente interligadas, a ponto de não haver maneira de distinguir nitidamente uma da outra”. Assim uma voz considerada vulgar pode ser aceita pelos usos majoritários, ao mesmo tempo em que algo que nos falares centrais se considere arcaico pode ter vigência ainda em um falar periférico.

Tomando um exemplo do catalão; desde a perspectiva da atual norma, formas do presente do subjuntivo como diga por digui ou haja por hagi possuem valores dialetais (adscritas à área do valenciano principalmente), diacrônicos (entendidas como arcaísmo já que a língua medieval conservava desinências diferentes para a formação do presente de subjuntivo da primeira, da segunda e da terceira conjugação que depois confluíram no catalão central) e, inclusive, podem resultar vulgares (na perda de prestígio das formas antigas) ou estrangeiras (por serem mais próximas aos equivalentes do castelhano, diga, haya).

Em suma, as categorias expostas aparecem intimamente imbricadas e resulta extremamente complexo deslindar vulgarismos, barbarismos, arcaísmos e dialetalismos já que a língua sempre contém uma multiplicidade de formas diacrónicas e sincrónicas (VENUTI, 1998, p.10). Entendemos que existe ainda um problema ao usar essas categorias já que aqueles autores provavelmente não considerassem essas palavras da mesma forma que hoje são classificadas por lexicógrafos e gramáticos. Problematizar as marcas lexicais do corpus deve servir para adotar estratégias na língua de chegada que ultrapassem as formas mais usuais do vocabulário ativo e mergulhem no acervo léxico do português brasileiro para assim acolher a polifonia dos textos fontes na língua de chegada.

Francisco Javier Calvo del Olmo franciscoctl.ctl@gmail.com

Prof. Dr., Universidade Federal do Paraná 


\section{Referências bibliográficas}

Berman, Antoine. A tradução e a letra ou o albergue do longínquo. [Tradução de Marie-Hélène Catherine Torres, Mauri Furlan, Andreia Guerini]. Rio de Janeiro: 7 Letras, 2007.

. A prova do estrangeiro: cultura e tradução na Alemanha romântica: Herder, Goethe, Schlegel, Novalis, Humboldt, Schleiermacher, Hölderlin. [Tradução de Maria Emília Pereira Chanut]. Bauru, SP: EDUSC, 2002.

. Pour une critique des tradutions: John Donne. Paris: Gallimard, 1995.

Branchadell, Albert; Lovell, Margaret West. (eds.). Less Translated Languages. Amsterdam/Philadelphia: John Benjamins, 2005.

Cronin, Michael. The Cracked Looking Glass of Servants: Translation and Minority Languages in a Global Age. The Translator, Vol. 4, No. 2: vol. 4, $\mathrm{n}^{\circ}$ 2, Special Issue, Translation and Minority. Manchester: St. Jerome, 1998. p. 145-62.

FABRA, Pompeu. Gramàtica catalana. Barcelona: Institut d'Estudis Catalans, 1980.

GABRIEL, Pere. Història de la cultura catalana, vol 4: Romantisme i Renaixença. Barcelona: Edicions 62, 1995.

HAGÈGE, Claude. Halte à la mort des langues. Paris: Odile Jacob, 2000.

KING, Stewart. Escribir la Catalanidad: lengua e identidades culturales en la Narrativa contemporánea de Cataluña. Woodbridge: Tamesis, 2005.

LAGARES, Xoan. Minorias linguísticas, políticas normativas e mercados. In: LAGARES, Xoán; BAGNO, Marcos. (orgs.) Políticas da norma e conflitos linguísticos. São Paulo: Parábola, 2011. p. 169-192.

LEVÝ, Jiří. The Art of Translation. Amsterdamã/Philadelphia: John Benjamins Publishing Company, 2011.

LlEAL, Coloma. Breu història de la llengua catalana. Barcelona: Barcanova,1992.

Milroy, James. Ideologias linguísticas e as consequências da padronização. In: LAGARes, Xoán Carlos; BAGNO, Marcos. Políticas da norma e conflitos linguísticos. São Paulo: Parábola, 2011. p. 49-88.

Monteagudo, Henrique. Variação e norma linguística: subsídios para uma (re)visão. In: LAGARES, Xoán Carlos; BAGNO, Marcos. Políticas da norma e conflitos linguísticos. São Paulo: Parábola, 2011. p. 15-48.

Olmo, Francisco Javier Calvo del. Tradução, língua e identidade em poetas occitanos e catalães do século XIX: elementos para uma tradução entre línguas românicas. Florianópolis. 2014. 418 f. Tese (Doutorado em Estudos da Tradução) - Programa de Pós-Graduação em Estudos da Tradução, Universidade Federal de Santa Catarina, Florianópolis. Disponível em http://www.pget.ufsc.br/curso/teses/Francisco_Javier_Calvo_del_Olmo__Tese.pdf, acesso em 06 jan. 2015.

RIBERA LLOPIS, Joan. Literaturas catalana, gallega y vasca. Madrid: Playor, 1982.

RuBIÓ I BALAGUER, Jordi. Història de la literatura catalana. Barcelona: Publicacions de l'Abadia de Montserrat, 1989.

Venuti, Laurence. The Scandals of Translation. Towards an ethics of difference. Londres/Nova Iorque: Routledge, 1998. 


\section{Sítios eletrônicos e dicionários:}

www.aulete.com.br/

www.enciclopedia.cat/

www.dicionari.cat

www.rae.es

www.dcvb.iecat.net/

www.vilaweb.cat 